\title{
Short-stemmed hybrid lines derived from crosses of triticale with the synthetic wheat
}

\author{
Aminov N.Kh. ${ }^{1 *}$, Mehdiyeva S.P. ${ }^{1}$, Adonina I.G. ${ }^{2}$, Salina E.A. ${ }^{2}$ \\ ${ }^{1}$ Genetic Resources Institute, ANAS, Baku, Azerbaijan \\ ${ }^{2}$ Institute of Cytology and Genetics, SB RAS, Novosibirsk, Russia \\ *e-mail: anaib@rambler.ru
}

We present here the study results on plant height $(\mathrm{PH})$ trait of triticale-like plants derived from triticale $\times$ synthetic wheat cross, in which the maternal plant is the locally produced hexaploid triticale ABR (genome AABBRR, $2 n=42$ ) with $\mathrm{PH}=88 \pm 16.97 \mathrm{~cm}$ and the paternal plant is the locally produced synthetic wheat ADS [(T. beoticum $\times$ Ae. taushii $) \times$ $\times$ Ae. speltoides, genome AADDSS, $2 n=42$ )] with $\mathrm{PH}=110 \pm 14.14 \mathrm{~cm}$. The maternal plant ABR is differentiated from other triticales by its obtaining in 1975 without any embryo rescue technique or hormone treatment procedure from sexual hybridization between Tanaka's (produced in Japan, Kyoto, AD 221-16a, in VIR- k-45918) synthetic wheat $\mathrm{ABD}(T$. durum $\times$ Ae. squarrosa var. meyeri, genome AABBDD, $2 n=42)$, $\mathrm{PH}=950 \pm 7.87 \mathrm{~cm}$ and local weed rye Secale cereale ssp. segetale (genome RR, $2 n=14$, collected from Lerik (Azerbaijan)), $\mathrm{PH}=1150 \pm 21.21 \mathrm{~cm} . \mathrm{F}_{1}$ plants from this cross with $\mathrm{PH}=110 \mathrm{~cm}$ had 28 chromosomes and after selfing in field conditions without any colchicine treatment the segregated $\mathrm{F}_{1}$ plants with 56 chromosomes were obtained. The above-mentioned triticale ABR with the chromosome number 42 was selected from late selfed generations based on such desirable traits as short stem, large spike, early heading time, flag leaf width and etc. Starting from 1980 the triticale ABR was included in numerous crosses with many wheats $(4 x, 6 x)$, triticales $(4 x, 6 x, 8 x)$ and wheatalien amphiploids $(6 \mathrm{x}, 8 \mathrm{x})$ for the study its morphotype formation diapason and obtain morphotypes with novel traits. Selected for current study the 8 short-stemmed hybrid lines are the segregants obtained from the same selfed $\mathrm{F}_{4}$ plant that was derived from cross of triticale ABR with synthetic wheat ADS made in 2007. The range of PH for this sister plants was varied from $43 \mathrm{~cm}$ up to $66 \mathrm{~cm}$. GISH analysis showed that the short stemmed line from this group has 42 chromosomes, 12 of which are rye chromosomes. 